\title{
Census of the Southern Giant Petrel population of the Falkland Islands 2004/2005
}

\author{
TIM A. REID and NIC HUIN
}

\section{Summary}

A complete census was taken of all colonies of Southern Giant Petrels Macronectes giganteus within the Falkland Islands in 2004/05. The breeding population of the islands was estimated to be approximately 19,529 pairs (range 18,420-20,377). Southern Giant Petrels were found to breed in 38 locations around the islands, with colony size varying from one to 10,936. The majority of colonies were concentrated around the south of Falkland Sound, and to the west of West Falkland. Whilst there has been no previous census of the total population of the islands, there is a strong indication that the population has increased since the 1950s. The reasons for such an increase in population remain unclear in light of current knowledge. Development of our understanding of the breeding biology and demography of this species in the Falkland Islands is necessary, as is the need to conduct such a census every five years, with a few key colonies to be monitored every season. From the results obtained here, the conservation status of the Southern Giant Petrel, currently listed as 'Vulnerable', could be downgraded to 'Near Threatened'.

\section{Introduction}

Concerns have been raised over the conservation status of many species of albatross and petrels throughout the world. These concerns derive from observations of significant numbers of these seabirds being killed in longline (e.g. Brothers 1991; Murray et al. 1993; Brothers 1995; Reid et al. 2004) and trawl (Bartle 1991; Sullivan et al. 2006) fisheries. In addition, breeding colonies for many species of albatross and petrels have been observed to be in decline over the corresponding period (Gales 1998; Huin 2001).

In 2002/2003 it was estimated that 100 Southern Giant Petrels Macronectes giganteus were killed in the Falkland Islands finfish trawl fishery (Sullivan et al. 2006) while limited data has indicated similar rates of mortality in 2001/2002 and in 2003/2004 (Sullivan and Reid 2002; 2004). The Falkland Islands breeding population was estimated to be in the order of 5,000-10,000 pairs between 1983 and 1992 (Woods and Woods 1997). Woods (1975) suggested the population had increased in the late $19^{\text {th }}$ and early $20^{\text {th }}$ centuries due to sheep farming (through the predation of carcases and lambs or still-borns), but had declined in the middle part of the $2 \mathrm{O}^{\text {th }}$ century due to persecution and egg collecting for human consumption.

The waters around the Falklands Islands have been shown to be important foraging grounds for the Southern Giant Petrel. They are frequently encountered during at-sea surveys (White et al. 2002) and around fishing vessels (pers. obs.). Despite this, satellite tracking of birds from South Georgia has generally shown that few utilise the waters in the region of the Falkland Islands (Birdlife International 2004, Gonzales-Solis et al. 2000). It has been suggested that the at-sea distribution of Falkland birds is largely mutually exclusive to those from South Georgia (Croxall and Woods 2002).

The most recent estimate of the world-wide population of Southern Giant Petrels (from the late 1990s) is approximately 31 ,000 pairs, which is a decline of $17 \%$ from the previous estimate 
of 38,000 pairs made in 1985 (Patterson et al. in press). For this reason the species has been classified by IUCN as 'Vulnerable'. The decline has been attributed to a number of causes, including fishing mortality, declines in the population of southern elephant seals, and human disturbance at colonies, where they are extremely sensitive (Brooke 2004).

There is concern over the status of the Southern Giant Petrel in the Falkland Islands because of the species' Vulnerable status, identified fishery mortalities in local waters, and the fact that $>10 \%$ have been previously estimated to breed there (Patterson et al. in press). In the Falklands there is currently no accurate estimate of the actual population size, and no knowledge of what the population trends are. Woods (1975) suggested the population had increased because Darwin did not comment on their presence when visiting in the 1830s. However he mainly stayed in the north-east of East Falkland, neither visiting Lafonia or West Falkland, and hence did not go to the areas where the species predominantly breeds (Armstrong 1992). Woods and Woods (1997) suggested the population increased during the 1800 due to the provision of food from sheep carcases, but declined during the I9oos through persecution. Therefore, the aims of this study are: i) to establish the current breeding status of the Southern Giant Petrel on the Falkland Islands; ii) to investigate population trends on the Falkland Islands; and iii) to establish its local and global conservation status by examining the implications of the first two issues.

\section{Methods}

Known or suspected colonies were identified by searching through the Falklands Conservation database for reports of sightings of colonies, and by interviewing all Falkland Islands landowners with coastline on their land (where Southern Giant Petrels potentially breed). A full census of all known and suspected colonies in the Falkland Islands was conducted between November 2004 and March 2005. Discrete colonies were found on all except four islands; Steeple Jason had four colonies, while East Falkland had a number of colonies, with most in the southern, Lafonia, area. On Barren and George Islands, nests were scattered over a wide area.

Two methods were used to make counts of birds in colonies; ground counts and aerial counts. For ground counts, birds were counted using binoculars at a distance from which the total colony could be observed without disturbing the birds within it. This distance varied between colonies. Aerial counts were made from multiple digital photographs taken from an aeroplane (Islander plane from Falkland Islands Government Air Service). Photographs were taken as the aircraft passed parallel to the colony at a height of approximately $300 \mathrm{~m}$. Digital photographs were then examined using Corel Draw software to join multiple photographs and to mark individual nests. All counts were made by two observers (NH \& TR), each of whom repeated the counts at least twice.

Counts were made during two periods. In November and December, II colonies were visited and all nests with incubating adults were counted. During this period, standing adults and birds not sitting on an obvious nest were not included in the counts. When both adults were present on a nest, they were counted as a single breeding pair. Counts at this time of year were defined as Apparently Occupied Nests (AON), as defined by Cruewels et al. 2005. A further five colonies were surveyed by aeroplane and the same method of counting breeding pairs was used as above. All birds sitting below the high water mark were regarded as non-breeding individuals. The high water mark was identified by the position of tidal debris on the beach. One problem with counts of AON made from distant vantage points is the possibility that some of the adults sitting on scrapes within colonies may not be on eggs. This is likely to bias the AON counts upwards.

Second counts were made after the chicks had hatched. All five colonies photographed previously were overflown again during the chick-rearing period. Counts were made of chicks Actual Chicks (AC) as defined by Cruewels et al. (2005). When chicks were left alone in February, individual chicks were counted, but due to the poor quality of photographs from two colonies, photographs from mid-January were used. In this case, both chicks left alone and nests with adults in attendance were counted. Twenty-nine colonies were surveyed by ground counts, 
four of which were already counted during the incubation period and one of which was also surveyed by air during both periods.

Fourteen colonies were counted during both incubation and chick-rearing, giving a ratio of AON/AC. Three of these colonies were only partially counted. The mean of this ratio was then used to estimate the original AON for all colonies where only chicks were counted. Due to the range of breeding success, such conversion has an inherently large error rate. Therefore, when colonies were counted during both incubation and chick-rearing, the values obtained during incubation were retained as the most accurate.

At all colonies, whether counted from the ground or by aerial photographs, multiple counts were conducted until all counts fell within $5-10 \%$ of each other. Several factors contributed to the final error that such census work creates. Firstly, variation in individual counts of adults produces a source of error. This error was estimated by calculating the minimum and maximum number of adults counted at each site. Secondly, similar variation exists within counts of chicks and the error was estimated in the same way as in the first point.

The colony on Governor Island and small parts of the colonies on Steeple Jason were counted both from land and from aerial survey. There was no significant difference between the two methods, but ground survey provided more accurate results (less variation between repetitive counts). Counts from ground survey for both Governor and Steeple Jason islands were therefore retained in the final calculations.

Special effort was made to look for Northern Giant Petrel Macronectes halli and white morph Southern Giant Petrel, because both are common visitors in the Falkland Islands waters, especially during winter months (White et al. 2002).

\section{Colony description}

The majority of colonies around the islands were on bare earth. Usually this was either sand or peat. Some colonies were on areas of shingle and shingle or sand spits. A few nests were situated close to tussock bogs or sand grass, though no colonies were situated within areas of tussock. Many were close to the high water line, and at times have been totally or partially washed out. On Steeple Jason one colony was on bare decomposed peat, and two were on bare earth amongst low grassland.

Colony sizes ranged from a single bird to 10,936 pairs. On several islands, including the largest on Sandy Cay, the entire colony was in one area and was relatively compact. However, on others, such as George and Barren Islands large numbers of breeding pairs are present, but these are scattered widely around the coasts of the islands in groups of $1-430$ chicks.

\section{Results}

Counts were made of the number of breeding pairs in 14 islands/colonies (nine by ground counts and five by aerial photography) during the incubation stage of breeding (Table 1 ). Four of these had no breeding birds (all in Lafonia). These colonies had a total of $16,099 \mathrm{AON}$, with a range in counts of 15,906-16,303.

Thirty-three colonies were counted during chick rearing (six by aerial photography; Table 1 ). Four colonies that had been visited during incubation and that did not have any breeding pairs were not visited during chick rearing. Colonies only counted during chick-rearing had a total of 2,529 AC present (range 2,506-2,550).

One colony that was known previously to have had breeding pairs (Beauchêne Island) was not visited during 2004/2005 for logistical reasons. It was visited during a survey of albatrosses in the summer of 2005/2006, when six AON were counted.

Eleven entire colonies and sections of two colonies had counts made during incubation and during chick rearing (Table 1 ). The ratio of the $\mathrm{AC} / \mathrm{AON}$ was estimated to be $63.6 \%$, with a range of $38-100 \%$. 
Table 1. Summary of breeding colonies of southern Giant Petrels in the Falkland Islands.

\begin{tabular}{|c|c|c|c|c|c|c|c|c|c|}
\hline \multirow[t]{2}{*}{ Site } & & \multicolumn{3}{|c|}{ Adult counts (AON) } & \multicolumn{3}{|c|}{ Chicks counts (AC) } & \multirow{2}{*}{$\begin{array}{l}\text { Estimated } \\
\text { Number of pairs } \\
(\mathrm{AON})\end{array}$} & \multirow{2}{*}{$\begin{array}{l}\text { Breeding } \\
\text { success } \\
\%\end{array}$} \\
\hline & & Method & Date & $\begin{array}{l}\text { Number of } \\
\text { pairs }\end{array}$ & Method & Date & $\begin{array}{l}\text { Number of } \\
\text { chicks }\end{array}$ & & \\
\hline \multirow[t]{5}{*}{ Steeple Jason } & The Neck & direct & 08/12/04 & 992 & direct & 05/02/05 & 629 & 992 & 63.41 \\
\hline & NW End & & 08/12/04 & 234 & & $05 / 02 / 05$ & 89 & 234 & 38.03 \\
\hline & Above EastBBA & & 08/12/04 & 2 & & 05/02/05 & 2 & 2 & 100.00 \\
\hline & AboveWestBBA & & 08/12/04 & 212 & & $05 / 02 / 05$ & 166 & 212 & 78.30 \\
\hline & Total & & & 1,440 & & & 886 & 1,440 & \\
\hline Jason West Cay & & & & & direct & 28/04/05 & 2 & 3 & \\
\hline Grand Jason & & & & & direct & 08/02/05 & 559 & 762 & \\
\hline Beauchêne Island & & direct & 28/06/05 & 6 & & & & 6 & \\
\hline Sea Lion Island & & & & & direct & 18/01/05 & 14 & 21 & \\
\hline \multirow[t]{11}{*}{ Lafonia } & Fanny point & direct & $15 / 11 / 04$ & 17 & direct & 11/01/05 & 16 & 17 & 94.12 \\
\hline & False Bull point & direct & $15 / 11 / 04$ & 9 & direct & 11/01/05 & 8 & 9 & 88.89 \\
\hline & Saw Rincon & direct & $16 / 11 / 04$ & o & & & & o & \\
\hline & Low Rincon & direct & $16 / 11 / 04$ & o & & & & o & \\
\hline & Motley point & direct & 16/11/04 & $\mathbf{1}$ & & & & 1 & \\
\hline & Long Creek & direct & $17 / 11 / 04$ & $\mathbf{o}$ & & & & o & \\
\hline & Piojo point & direct & $17 / 11 / 04$ & o & & & & o & \\
\hline & Cattle point rincon & & & & direct & 03/03/05 & $o^{*}$ & & \\
\hline & Cattle point rincon south & & & & direct & $03 / 03 / 05$ & $o^{*}$ & & \\
\hline & Driftwood point & & & & direct & $03 / 03 / 05$ & 7 & 10 & \\
\hline & Mutiny point & & & & direct & $03 / 03 / 05$ & 14 & 19 & \\
\hline Pebble Island & & & & & direct & 30/01/05 & 46 & 63 & \\
\hline NW Passage islet & & & & & & $15 / 02 / 02$ & $o^{*}$ & & \\
\hline Low Island & & & & & direct & 03/02/05 & 14 & 19 & \\
\hline Hope point & & & & & direct & 03/02/05 & $\mathbf{I}$ & 1 & \\
\hline Governor Island & & photo & $\mathrm{O} 4 / 12 / 04$ & 723 & both & 10/02/05 & 351 & 723 & 48.55 \\
\hline West Island & & & & & direct & 10/02/05 & 44 & 60 & \\
\hline Dyke Island & Monkey point & & & & direct & Io/02/05 & 34 & 46 & \\
\hline Ten Shilling Bay & & & & & & $11 / 02 / 05$ & $o^{*}$ & & \\
\hline Albermale & Rookery point & & & & direct & $11 / 02 / 05$ & 12 & 16 & \\
\hline Barren Island & all & & & & direct & $12 / 02 / 05$ & 1,103 & 1,504 & 73.08 \\
\hline
\end{tabular}


Table 1. Continued.

\begin{tabular}{|c|c|c|c|c|c|c|c|c|c|}
\hline \multirow[t]{2}{*}{ Site } & & \multicolumn{3}{|c|}{ Adult counts (AON) } & \multicolumn{3}{|c|}{ Chicks counts (AC) } & \multirow{2}{*}{$\begin{array}{l}\text { Estimated } \\
\text { Number of pairs } \\
(\mathrm{AON})\end{array}$} & \multirow{2}{*}{$\begin{array}{l}\text { Breeding } \\
\text { success } \\
\%\end{array}$} \\
\hline & & Method & Date & $\begin{array}{l}\text { Number of } \\
\text { pairs }\end{array}$ & Method & Date & $\begin{array}{l}\text { Number of } \\
\text { chicks }\end{array}$ & & \\
\hline George Island & all & & & & direct & $13 / 02 / 05$ & 441 & 602 & 73.58 \\
\hline Swan Island & all & & & & direct & $14 / 02 / 05$ & 48 & 65 & \\
\hline Carcass Island & & & & & direct & 15/01/05 & 2 & 3 & \\
\hline Bleaker Island & all & & & & direct & $30 / 01 / 05$ & 128 & 175 & \\
\hline Burnt Islet & & & & & direct & $15 / 02 / 05$ & 4 & 5 & \\
\hline Johnson Harbour & Black Point & & & & direct & 26/01/05 & 6 & 8 & \\
\hline Elephant Beach & Smylies Black point & & & & direct & $22 / 02 / 05$ & $0^{*}$ & & \\
\hline Cape Dolphin & Swan pond point & & & & direct & $22 / 02 / 05$ & $\mathbf{I}$ & 1 & \\
\hline North East & Hutchy's south reef & & & & direct & $03 / 03 / 05$ & $o^{*}$ & & \\
\hline Lively & Enderby point & & & & direct & $03 / 03 / 05$ & 14 & 19 & \\
\hline Rincon Grande & & & & & direct & $03 / 03 / 05$ & 12 & 16 & \\
\hline Penn Island & all & photo & $04 / 12 / 04$ & 1,543 & photo & $04 / 02 / 05$ & 643 & 1,543 & 41.67 \\
\hline Speedwell Island & Phillips point & & & & photo & $04 / 02 / 05$ & 23 & 31 & \\
\hline Speedwell Island & South tip & & & & photo & $04 / 02 / 05$ & $o^{*}$ & & \\
\hline Third Passage & & photo & $27 / 12 / 04$ & 405 & photo & $04 / 02 / 05$ & 233 & 405 & 57.53 \\
\hline Elephant Cays & Golden Knob & photo & 08/12/04 & 1,019 & photo & $14 / 01 / 05$ & 576 & 1,019 & 60.19 \\
\hline Elephant Cays & Sandy Cay & photo & $08 / 12 / 04$ & 10,936 & photo & $14 / 01 / 05$ & 7,474 & 10,936 & 68.34 \\
\hline Total counted & & & & 16,099 & & & 12,716 & 19,529 & 68.13 \\
\hline
\end{tabular}

Noter: bold numbers are values used for computation of total number of breeding pairs

Note2: breeding success in italic come from subsample of colony only 
Table 2. Numbers of breeding pairs recorded historically at colonies mentioned in the text.

\begin{tabular}{|c|c|c|c|c|c|}
\hline Location & Year & Date & Number & Unit & References \\
\hline \multirow[t]{3}{*}{ Elephant Cays } & $1950 \mathrm{~s}$ & & hundreds & & Cawkell and Hamilton (1961) \\
\hline & $1986 / 1987$ & & $1, \mathrm{OOO}$ & & Woods and Woods (1997) \\
\hline & $2004 / 2005$ & $8 / 12 / 2004$ & 11,955 & $\mathrm{AON}$ & this study \\
\hline \multirow[t]{4}{*}{ Steeple Jason } & $1950 \mathrm{~s}$ & & few dozen & & Cawkell and Hamilton (1961) \\
\hline & $1987 / 88$ & & 300 & & Thompson, FC \\
\hline & $2000 / 2001$ & Nov 2000 & 1,051 & $\mathrm{AON}$ & Huin, pers.obs \\
\hline & $2004 / 05$ & $8 / 12 / 2004$ & 1,440 & $\mathrm{AON}$ & this study \\
\hline \multirow[t]{2}{*}{ Grand Jason } & 1996 & & 120 & & FC \\
\hline & $2004 / 2005$ & $8 / 02 / 2005$ & 559 & $\mathrm{AC}$ & this study \\
\hline \multirow[t]{4}{*}{ George Island } & $1950 \mathrm{~s}$ & & not present? & & Cawkell and Hamilton (1961) \\
\hline & 1961 & & 30 & & Woods and Woods (1997) \\
\hline & 1986 & & 250 & & Woods and Woods (1997) \\
\hline & $2004 / 2005$ & $13 / 02 / 2005$ & 441 & $\mathrm{AC}$ & this study \\
\hline \multirow[t]{4}{*}{ Sea Lion Island } & $1950 \mathrm{os}$ & & hundreds & & Cawkell and Hamilton (1961) \\
\hline & $1986 / 1987$ & & 5 or 6 pairs & & Woods and Woods (1997) \\
\hline & 1990 & & 20 & & Thompson, FC \\
\hline & $2004 / 2005$ & $18 / 01 / 2005$ & 14 & $\mathrm{AC}$ & this study \\
\hline \multirow[t]{2}{*}{ Governor Island } & 1989 & & 250 & & Thompson, FC \\
\hline & $2004 / 2005$ & $4 / 12 / 2004$ & 723 & $\mathrm{AON}$ & this study \\
\hline \multirow[t]{3}{*}{ Pebble Island } & 1986 & & 19 & & Woods and Woods (1997) \\
\hline & 1990 & Dec 1990 & 50 & & Woods and Woods (1997) \\
\hline & $2004 / 2005$ & $30 / 01 / 2005$ & 46 & $\mathrm{AC}$ & this study \\
\hline
\end{tabular}

The number of AC for the islands was 12,716 (Table 1). From this, it was estimated that a total of 19,529 AON of Southern Giant Petrels (range 18,420-20,377) breed at 38 locations in the Falkland Islands (Table I). This gives an error rate of the estimate of $10.02 \%$. There were two major concentrations of breeding sites and numbers; at the southern end of Falkland Sound $(72 \%)$, and off the west of West Falkland (26\%) (Fig.I). The island with the greatest number of breeding pairs was Sandy Cay, in the Elephant Cays, with 10,936 breeding pairs. Other colonies with $>1,000$ pairs were Barren Island ( 1,504 pairs), Penn Island ( 1,543 pairs), Steeple Jason ( 1,440 pairs) and Golden Knob ( 1,019 pairs).

All birds observed were Southern Giant Petrels. No Northern Giant Petrels were observed. All adults observed within or near colonies were southern Giant Petrels. No birds counted, either directly or from the air, were of the white morph.

\section{Discussion}

\section{Status within the islands}

The estimated breeding population of southern Giant Petrels for the Falkland Island is 19,523 pairs. This is much higher than previous estimates of their population within the islands (Woods and Woods 1997). In 1982 the population was estimated at 3,200 breeding pairs (Croxall et al. 1984). Whilst previous estimates are too vague to estimate a rate of increase, there nevertheless seems to be clear evidence for the breeding population within the Falkland Islands to be increasing.

Most known colonies in the islands have increased (Table 2). Those colonies that have declined were all small to begin with, thus the clear trend is for increasing real numbers of birds breeding in the islands, rather than unknown colonies being found. In the case of the largest colony, at the Elephant Cays, one colony is reported as present during the 1950s, where now two exist. Given 


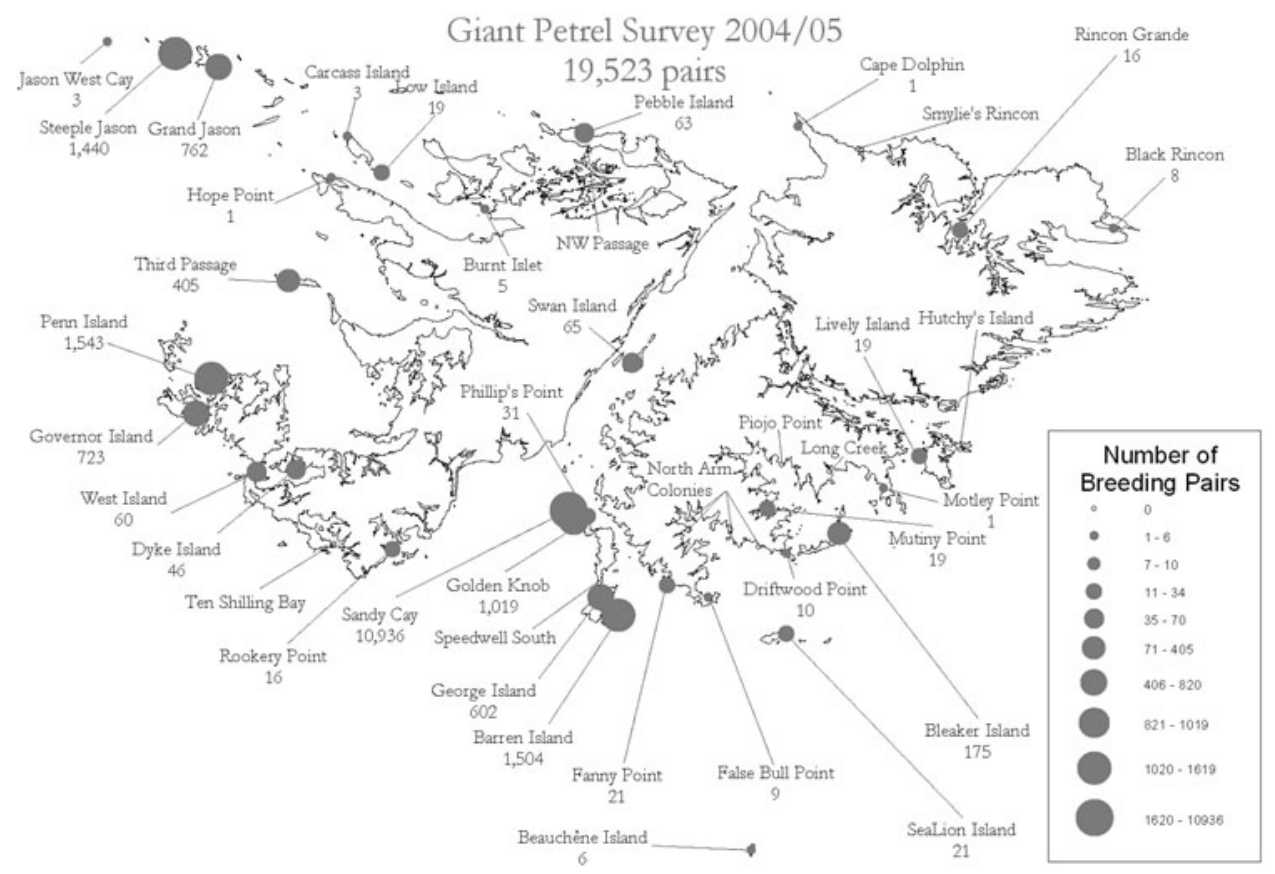

Figure 1. Distribution and size of breeding colonies of southern Giant Petrels within the Falkland Islands (number given is the actual or estimated number of breeding pairs).

the current large size of the colonies and the small size of the islands, it is extremely unlikely that a large colony was overlooked.

Southern Giant Petrels are difficult to census, as in many areas, including the Falkland Islands, they are very prone to disturbance at their colonies (pers. obs.). When approached, birds will frequently abandon their nests leaving eggs open to predation. This can affect the results of censuses. Thus during the current census, colonies were counted from distant vantage points or from aeroplanes in order to minimise disturbance. There is some indication in the data of a decrease in the ratio $\mathrm{AC} / \mathrm{AON}$ with increasing colony size (with the exception of the largest colony at Sandy Cay). It was not possible to test whether this is a real trend or if it is the result of the methodology. As larger colonies tend to be counted from a greater distance, this may result in an increase in the number of non-breeding birds being counted as nesting birds. If the latter is the case, there is some potential for biasing the counts of AON upwards. Counts of actual chicks do not have this bias, but they do not take account of the numbers of nests that failed earlier in the season.

Most colonies (and all the largest ones) are situated in either the lower end of the Falkland Sound, or on islands to the west of West Falkland. These areas are closest to the extensive areas of the rich waters of the Patagonian shelf to the west of the Falklands (Croxall and Woods 2002).

\section{Reasons for the change in the status within the Falkland Islands}

Within the Falkland Islands waters, fisheries mortality occurs (Sullivan et al. 2006). However this is apparently insufficient to have a significant effect on the population status. Within Falkland Islands waters, mitigation measures implemented in 2004 by trawlers to reduce the impact on albatrosses, correspondingly benefit the Southern Giant Petrel. 
Human disturbance to breeding colonies is often mentioned as a cause of declines in Southern Giant Petrel populations (Brooke 2004; Patterson et al. in press). This is unlikely to be the case now within the Falkland Islands, as most islands that they breed on, though not reserves, are relatively undisturbed. Of the ten largest colonies with over 1oo breeding pairs, only two of them have more or less permanent housing (George and Bleaker Islands), and three have continuing sheep farming (George, Barren and Bleaker Islands). Six of these islands are very rarely (or never) visited. Four islands are privately owned, and are never visited. Steeple Jason currently has a predominantly unmanned research station (used for approximately 2-4 weeks each summer, though this is likely to increase), as well as having some helicopter tourism. Governor Island and Steeple and Grand Jason have been used more extensively for sheep farming in the past (Steeple and Grand not since the late 1960s, Governor not since the 1980s), though the other islands were probably never very important for farming. Nowadays, persecution of Southern Giant Petrels near sheep carcasses is almost certainly non-existent and egg collecting has stopped.

It is not known if food availability has changed around the Falkland Islands, as no diet studies have been conducted. The Southern Giant Petrel is an opportunist scavenger (Marchant and Higgins 1990). In South Georgia, Macquarie Island, Davis Station (Antarctica) and Signy Island, penguins have been found to make up over $70 \%$ of their diet, though they also eat crustaceans, fish and cephalopods (Marchant and Higgins 1990). In the Falklands, out of the potential birds that may be scavenged from, Rockhopper Penguin Eudyptes chrysocome and Black-browed Albatross Diomeda melanophris populations have been declining recently, while Gentoo Penguins Pygoscelis papua, while fluctuating greatly, have remained at approximately the same level. Of the seal species that breed within the islands, Southern Sea-lions Otaria byronia and South American Fur-seals Arctocephalus australis have not yet recovered from sealing early in the $20^{\text {th }}$ century, while Southern Elephant Seals Mirounga leonina are only present in small numbers. Opportunities for feeding at sea may also have opened up with the decline in the population of the Black-browed Albatross. Flocks of over 50 Southern Giant Petrels frequently occur around trawlers operating around the Falklands to take fisheries offal (T. Reid pers. obs.). Up to 40 trawlers operate within Falklands Islands waters during spring. Therefore, perhaps Falkland Island birds are using trawlers as a significant food source, but there must be other sources.

\section{Global conservation status}

IUCN recently classified southern Giant Petrels as 'Vulnerable' due to an inferred decline of $30 \%$ over 64 years (three generations), with an estimated decline of the worldwide breeding population from 38,000 to 31,000 between the 1980 s and the late 1990 (Patterson et al. in press). The status of breeding populations around the Southern Ocean varies considerably. The population at Heard Island declined by 50\% between the 1960s and 1980s, from 4,000 in the 1950 s to 2,350 in 1980 (Marchant and Higgins 1990, Patterson et al. in press), while that at Macquarie Island also declined by 50\% during this period (Marchant and Higgins 1990). The population on Marion Island increased in the mid-1990s, but then declined rapidly in the late I990s (Nel et al. 2002). Other colonies, such as South Georgia and Possession Island (Crozet) have remained stable or increased (Patterson et al. in press). Antarctic populations were recently listed as regionally Critically Endangered due to a $90 \%$ decline in three generations, with declines in many Antarctic Peninsula populations (e.g. $>50 \%$ at Signy Island and Dumont D’Urville; Marchant and Higgins 1990). However more recent censuses from Signy Island indicate the population to be increasing since the mid-1980s (BAS unpubl.). This decline has been attributed to a combination of causes; mortality due to long line fisheries for example resulted in 2,000-4,000 deaths in 1997, while it has also been suggested that declines in the population of Southern Elephant Seals, and human disturbance have contributed (Brooke 2004). Nevertheless, in some other colonies the populations have remained relatively stable (e.g. South 
Table 3. Percentage of the world population of southern Giant Petrels within colonies that are increasing or decreasing (from Patterson et al. in press, plus figures from this census for the Falkland Islands, British Antarctic Survey unpubl., and Quintana et al. 2006).

\begin{tabular}{lcc}
\hline Population trend & Population & Percent \\
\hline Unknown & 13,708 & 28.7 \\
Stable & 1,011 & 2.1 \\
Decrease & 8,301 & 17.4 \\
Increase & 24,714 & 51.8 \\
\hline
\end{tabular}

Georgia, Iles Crozet, Gough Island), while for many colonies there is little reliable or recent data. For some colonies the declines may no longer be occurring.

The figures from this census of the Falkland Islands population suggest major changes in the global status of this species. Using data from Patterson et al. (in press) but with the Falkland Islands figures updated from this census, the estimated world population would be 47,734 breeding pairs. On current published figures, the percentage of the world population breeding in the Falkland Islands would be $41 \%$ (including $23 \%$ on Sandy Cay). Over $50 \%$ of the world population is in colonies that are apparently increasing (Table 3), while less than $20 \%$ is in colonies that are decreasing. This indicates that population declines are now estimated to fall below $30 \%$ over 64 years and that the species may warrant downlisting to Near Threatened. Caution is warranted given that significant numbers continue to be killed in fisheries (SCCAMLR 2003, Sullivan et al. 2006). This mortality may potentially influence colonies to differing extents, depending on the regions where the birds forage, and the type of fishing.

\section{Conclusions}

Results presented in this paper indicate the Southern Giant Petrel to be more numerous in the Falkland Islands than previously thought. The population is apparently increasing, though the reasons for this are uncertain. Nevertheless, there continues to be some mortality in fisheries. Thus, the species should be regularly monitored to see if the current population increase continues, if the population reaches a constant level, or if it begins to decline. Demographic traits of this species are likely to be similar to the Black-browed Albatross and a similar monitoring regime should be put in place. This would involve repeating the full islands census every five years and monitoring some easily accessible colonies annually both at least for breeding number $(\mathrm{AON})$ and breeding success (AC). To gain a fuller understanding of the status of the species, it is imperative for censuses to be conducted at a number of sites worldwide that have not been visited since the 1980 or oarlier.

\section{Acknowledgments}

The project was funded by the United Kingdom Foreign and Commonwealth Office Overseas Territories Environmental Program (OTEP) and the Falkland Islands Government.

We wish to thank Eddie Andersen for flying the plane for the aerial photography work and supplying us with photos from the incubation period. Mark Plunkett assisted with counting aerial photographs. Michael Clarke and Ron Dixon assisted by driving the boat in order for us to do the majority of the survey, while Sam Miller also assisted in boat driving. Andy Black, Amy van Buren, Alex Jones, Grant Munro, Helen Otley, Emma Phillips, Mike and Phyll Rendell, Oli Yates, and especially Paola Palevecino assisted with counting, both in incubation and chick rearing periods. We also wish to thank all Falkland Islands landowners who assisted with information with regards colony locations and allowing us access to count their colonies. 


\section{References}

Armstrong, P. (1992) Darwin's desolate islands: a naturalist in the Falklands, 1833 and 1834. Chippenham, UK: Picton Publishing.

Bartle, J. A. (1991) Incidental capture of seabirds in the New Zealand subantarctic squid trawl fishery, 1990. Bird Conserv. Internat. 1: 351-359.

Birdlife International (2004) Tracking ocean wanderers: the global distribution of albatrosses and petrels. Results from the Global Procellariiform workshop, 1-5 September 2003, Gordon's Bay, South Africa. Cambridge, UK: Birdlife International.

Brooke, M. (2004) Albatrosses and petrels of the world. Oxford: Oxford University Press.

Brothers, N. (1991) Albatross mortality and associated bait loss in the Japanese longline fishery in the Southern Ocean. Biol. Conserv. 55: 255-268.

Brothers, N. (1995) An investigation into the cause of seabird mortality and solutions to this in the Spanish system of demersal longline fishing for Patagonian toothfish Dissostichus eleginoides in the South Atlantic Ocean. Tasmania, Australia: Parks and Wildlife Service.

Cawkell, E. M. and Hamilton, J. E. (1961) The birds of the Falkland Islands. Ibis 1oza: 1-27.

Croxall, J. P. and Woods, A. G. (2002) The importance of the Patagonian Shelf for top predator species breeding at South Georgia. Aquatic Conserv. Mar. Freshw. Ecosyst. 12: 101-118.

Croxall, J. P., McInnes, S. J. and Prince, P. A. (1984) The status and conservation of seabirds in the Falkland Islands. Pp. 271-292 in J. P. Croxall, P. G. H. Evans and R. W. Schrieber, eds. Status and conservation of the world's seabirds. Cambridge: ICBP. ICBP Tech. Publ. 2.

Cruewels, J. C. S., Stark, J. S., Woeher, E. J., van Franeker, J. A. and Ribic, C. A. (2005) Monitoring of a southern giant petrel Macronectes giganteus population on the Frazier Islands, Wilkes Land, Antarctica. Polar Biol. 28: 483-493.
Gales, R. (1998) Albatross populations: status and threats. Pp. $20-45$ in G. Robertson and R. Gales, eds. Albatross biology and conservation. Chipping Norton: Surrey Beatty and Sons.

Gonzales-Solis, J., Croxall, J. P. and Wood, A. G. (2000) Foraging partitioning between giant petrels Macronectes spp. and its relationship with breeding population changes at Bird Island, South Georgia. Mar. Ecol. Prog. Ser. 204: 279-288.

Huin, N. (2001) Census of the Black-browed Albatross population of the Falkland Islands 2000/2001. Stanley: Falklands Conservation.

Marchant, S. and Higgins, P. J. (1990) Handbook of Australian, New Zealand and Antarctic birds. Volume 1: Ratites to ducks. Melbourne: Oxford University Press.

Murray, T. E., Bartle, J. A., Kalish, S. R. and Taylor, P. R. (1993) Incidental capture of seabirds by Japanese Southern bluefin tuna longline vessels in New Zealand waters, 1988-1992. Bird Conserv. Internat. 3: 181-210.

Nel, D. C., Ryan, P. G., Crawford, R. J. M., Cooper, J. and Huyser, O. A. W. (2002) Population trends of albatrosses and petrels at sub-Antarctic Marion Island. Polar Biol. 25: 81-89.

Patterson, D. L., Woehler, E. J., Croxall, J. P., Cooper, J., Poncet, S. and Fraser, W. R. (in press) Breeding distribution and population of the northern Giant Petrel Macronectes halli and the southern Giant Petrel $M$. giganteus. Mar. Ornithol.

Quintana, F., Punta, G., Copello, S. and Yorio, P. (2006) Population and trends of the southern giant petrel (Macronectes giganteus) breeding in North Patagonia, Argentina. Polar Biol. 30: 53-59.

Reid, T. A., Sullivan, B. J., Pompert, J., Enticott, J. W. and Black, A. D. (2004) Seabird mortality associated with Patagonian toothfish (Disosstichus eleginoides) longliners in the Falkland Islands. Emu 104: 317-325.

SC-CAMLR (2003) Report of the twentysecond meeting of the Scientific Committee. Hobart: CCAMLR. 
Sullivan, B. and Reid, T. (2002) Seabird interactions/mortality with longliners and trawlers in Falkland Islands waters 2001/ o2. Stanley: Falklands Conservation.

Sullivan, B. and Reid, T. (2004) Seabird mortality in fisheries and mitigation techniques in Falkland Islands waters 2003/04. Stanley: Falklands Conservation.

Sullivan, B. J., Reid, T. A. and Bugoni, L. (2006) Seabird mortality on factory trawlers: the Falkland Islands experience. Biol. Conserv. 131(4): 495-504.
White, R. W., Gillon, K. W., Black, A. D. and Reid, J. B. (2002) The distribution of seabirds and marine mammals in Falkland Islands waters. Peterborough, UK: Joint Nature Conservation Committee.

Woods, R. W. (1975) The birds of the Falkland Islands. Shropshire: Anthony Nelson.

Woods, R. W. and Woods, A. (1997) Atlas of breeding birds of the Falkland Islands. Wiltshire: Anthony Nelson.

\section{T. A. REID*, N. HUIN}

Falklands Conservation, PO Box 26 Stanley Falkland Islands.e-mail: treid@utas.edu.au

* Author for correspondence. Current address: Antarctic Wildlife Research Unit, Zoology Department, Private Bag 5, University of Tasmania, Sandy Bay 7ooo, Tasmania, Australia.

Received 6 September 2006; revision accepted 23 July 2007 